\title{
Paying attention to reading: The neurobiology of reading and dyslexia
}

\author{
SALLY E. SHAYWITZ AND BENNETT A. SHAYWITZ \\ Yale University School of Medicine
}

\begin{abstract}
Extraordinary progress in functional brain imaging, primarily advances in functional magnetic resonance imaging, now allows scientists to understand the neural systems serving reading and how these systems differ in dyslexic readers. Scientists now speak of the neural signature of dyslexia, a singular achievement that for the first time has made what was previously a hidden disability, now visible. Paralleling this achievement in understanding the neurobiology of dyslexia, progress in the identification and treatment of dyslexia now offers the hope of identifying children at risk for dyslexia at a very young age and providing evidence-based, effective interventions. Despite these advances, for many dyslexic readers, becoming a skilled, automatic reader remains elusive, in great part because though children with dyslexia can be taught to decode words, teaching children to read fluently and automatically represents the next frontier in research on dyslexia. We suggest that to break through this "fluency" barrier, investigators will need to reexamine the more than 20-year-old central dogma in reading research: the generation of the phonological code from print is modular, that is, automatic and not attention demanding, and not requiring any other cognitive process. Recent findings now present a competing view: other cognitive processes are involved in reading, particularly attentional mechanisms, and that disruption of these attentional mechanisms play a causal role in reading difficulties. Recognition of the role of attentional mechanisms in reading now offer potentially new strategies for interventions in dyslexia. In particular, the use of pharmacotherapeutic agents affecting attentional mechanisms not only may provide a window into the neurochemical mechanisms underlying dyslexia but also may offer a potential adjunct treatment for teaching dyslexic readers to read fluently and automatically. Preliminary studies suggest that agents traditionally used to treat disorders of attention, particularly attention-deficit/hyperactivity disorder, may prove to be an effective adjunct to improving reading in dyslexic students.
\end{abstract}

No doubt since humans first began to read, there have been those who struggled with the printed word. The seeming ease with which most children learn to read contrasts sharply with the travails of a surprisingly large subgroup of children as they try to extract meaning from print. How we read and why some very bright children and adults struggle to read has intrigued and challenged generations of investigators. More recently, particularly with the

This work was supported by grants from the National Institute of Child Health and Human Development (P50 HD25802, RO1 HD046171, R01 HD057655).

Address correspondence and reprint requests to: Sally Shaywitz, Department of Pediatrics, Yale University School of Medicine, 333 Cedar Street, New Haven, CT 06510; E-mail: sally.shaywitz@yale.edu. advent of the powerful tools of modern neuroscience, the very act of reading has become visible. The ability to image reading (and dyslexia) has provided a neurobiological framework within which to incorporate advances in cognitive psychology, developmental psychology, linguistics, neurology, genetics, epidemiology, and education to provide an increasingly specified and fine-grained account of reading and dyslexia. The perspectives gained from such a multilevel integration, particularly emerging insights into the role of attentional processes in deciphering the code, suggest new avenues of scientific exploration and perhaps newer therapeutic targets and strategies to improving reading. We first consider how children learn to read and why reading is much more difficult than speaking. 


\section{How We Read}

Although print emerged from, and maintains its roots in, the language system, the differences between written and spoken language provide an account of why reading is difficult and speaking is easy. This relationship between spoken and written language is perhaps best captured by the statement, "Writing is not language, but merely a way of recording [spoken] language by visible marks" (Bloomfield, 1933, p. 21). A number of theories of dyslexia have been proposed, including phonological theory (Liberman, Shankweiler, \& Liberman, 1989; Ramus et al., 2003), rapid auditory processing theory (Tallal, 1980, 2000; Tallal, Miller, \& Fitch, 1993), visual theory (Livingstone, Rosen, Drislane, \& Galaburda, 1991; Lovegrove, Bowling, Badcock, \& Blackwood, 1980), cerebellar theory (Nicolson \& Fawcett, 1990; Nicolson, Fawcett, \& Dean, 2001), and magnocellular theory (Galaburda, Menard, \& Rosen, 1994; Livingstone et al., 1991; Stein, 2003; Stein \& Walsh, 1997). Ramus et al. (2003) provide a review and critique of the various theories. Of the several theories suggested, an explanation reflecting what is known about the relationship between spoken and written language, the phonological model, has received the most support (Hulme, Snowling, Caravolas, \& Carroll, 2005; Ramus et al., 2003; Rayner, Foorman, Perfetti, Pesetsky, \& Seidenberg, 2001; Shaywitz, 2003; Snowling, 2000).

To understand why print has meaning and why reading presents a challenge, we consider first the language system, and then why reading is more difficult than speaking. The language system is conceptualized as a hierarchy of component modules (Fodor, 1983); at the lowest level is the phonological module, dedicated to processing the elemental units of language, phonemes. The phonological module assembles the phonemes into words for the speaker and disassembles the words back into phonemes for the listener. Reflecting a process referred to as coarticulation, spoken language appears seamless to the listener, with no clues to its segmental nature (Liberman, Cooper, Shankweiler, \& StuddertKennedy, 1967). Thus, the word "mat" comprises three phonemes " $m$ " "aaa" "t" but the listener hears this as the holistic word "mat," not as three separate sounds. It is the seamless nature of spoken language, giving no clue to its underlying segmental nature, that presents an early challenge to the would-be reader.

Spoken language is observed in all societies on earth, and has been with us for hundreds of thousands of years. Exposing a baby to a natural speaking environment results in the development of spoken language; spoken language does not need to be specifically taught, and may even be innate. In contrast, print is artificial; many societies still rely primarily on spoken language and from an evolutionary perspective, reading is rather new, only several thousand years old (Lawler, 2001). Consequently, in contrast to spoken language, written language is acquired and must be taught. Learning to read requires multiple skills including developing an awareness that spoken language can be segmented into smaller elements (i.e., phonemes), identifying letters, learning the rules of how print maps onto sound, recognizing whole words not only accurately but also rapidly (automatically), acquiring a vocabulary, and extracting meaning from the printed word(s).

In the process of learning to read, a critical and, for some children, forbidding step is recoding the letters (orthography) into their sounds (phonology). It is not surprising that this process has been the focus of intense study. Over three decades ago researchers proposed two routes for transforming print into speech (Forster \& Chambers, 1973; Marshall \& Newcombe, 1973): a so-called lexical or more direct route and a sublexical or rule-based pathway. This dual route model of reading print aloud has been further elaborated, mainly through the work of Coltheart and colleagues (Coltheart, 1978, 1985; Coltheart, Curtis, Atkins, \& Haller, 1993; Coltheart \& Rastle, 1994; Harris \& Coltheart, 1986); more recently, a computational model of this process referred to as the dual route cascaded model has been proposed (Coltheart, Rastle, Perry, Langdon, \& Ziegler, 2001; see also Coltheart et al., 1993; Rastle \& Coltheart 1998, 1999a, 1999b). The lexical route relies on the mental (orthographic) lexicon where representations of printed words are stored; a reader sees a printed word, looks it up in his mental lexicon, activating representations in the phonological lexicon (referred to as addressed phonology) and reads the word aloud. 
In contrast, the sublexical route relies on the serial mapping, left to right, of each letter in a letter string to its corresponding sound (referred to as assembled phonology); once the letters are mapped, the word is read aloud. Given the vagaries of the English language, some words, for example, irregular words such as though and shoulder and yacht cannot be sounded out (their spellings do not follow the rules) and must be identified more holistically through the lexical route. In contrast, pseudowords that follow the rules but are made up and have never been seen by the reader previously are not present in the reader's lexicon and must be sounded out through the sublexical route, for example, scrower or thracting. Thus, within a dual route model, the critical process of phonological recoding (translating letters to sound) can occur via two different mechanisms: one, a lexical mechanism that addresses the phonological code directly from the stored lexical representations and the other, a sublexical mechanism that assembles the phonological code serially, letter-by-letter. As will be discussed below, these mechanisms may be represented in brain by separate, although obviously interrelated, left hemisphere neural systems, addressed phonology by a more ventral system and assembled phonology by a more dorsal system.

Beginning reading instruction focuses on teaching children the rules for mapping the orthography (letters) onto the elemental sounds of spoken language (phonemes). From a developmental perspective, children initially learn to read words by mapping letters to sounds, and eventually, it is thought, after reading and rereading a word correctly, the child can read the word not only accurately but also fluently (and, it is inferred, automatically). Fluent reading refers to the ability to read text not only accurately but also rapidly and with proper expression (National Reading Panel, 2000). As experience with reading instruction accumulates, it is increasingly clear that, although teaching children how the alphabetic system works achieves accurate reading, large numbers of children remain unable to read fluently (Lovett, Ransby, Hardwick, Johns, \& Donaldson, 1989; Shaywitz, 2003; Shaywitz, Morris, \& Shaywitz, 2008; Torgesen, Wagner, $\&$ Rashotte, 1997). The increasing appreciation of the importance and elusiveness of fluent reading, particularly its disruption in dyslexic readers, is evident in the most recent definition of dyslexia (discussed below). Although the previous definition refers to "single-word decoding" (Lyon, 1995), the newer, updated definition describes "difficulties with accurate and/or fluent word recognition," acknowledging converging data indicating the failure of the development of fluent reading as a hallmark of dyslexia that persists into adolescence and then adulthood, even when accuracy improves. The lack of fluent reading is observed clinically by reading that is effortful and slow; it is often considered the sine qua non of dyslexia, especially in young adult and adult readers (Bruck, 1998; Lefly \& Pennington, 1991; Shaywitz, 2003).

\section{Reading and Attention}

An assumption underlying the generation of phonological codes from print is that these processes are automatic and do not require much, if any, attentional resources (Gronau \& Frost, 1997; Johnston \& Castles, 2003; Lukatela \& Turvey, 1994a, 1994b; Luo, Johnson, \& Gallo, 1998; Perfetti, Bell, \& Delaney, 1988; Xu \& Perfetti, 1999). Recent evidence, however, questions this assumption, that is, the seemingly dogmatic belief that reading processes require only phonological mechanisms. For example, Reynolds and Besner (2006) suggest that attention is a critical, overlooked component, integral for translating print into speech, necessary for achieving fluent reading. Further evidence that attentional processes may be critical in reading comes from studies emphasizing the comorbidity of dyslexia and attention-deficit/hyperactivity disorder (ADHD), disorders that clinically are frequently observed in the same individual (August \& Garfinkel, 1990; Dykman \& Ackerman, 1991; Shaywitz, Fletcher, \& Shaywitz, 1994; Willcutt \& Pennington, 2000). Below we review the theoretical studies that provide further support for the proposal that attentional mechanisms may play an important role in reading, particularly in the development of fluent, automatic reading.

An automatic process is often viewed as synonymous with a process not requiring effort or attention. Within such a conceptualization, skilled or fluent reading is considered to be 
automatic and not dependent on attentional mechanisms. The development of automaticity or skill has long been linked to practice, based on the notion that "repetition progressively frees the mind from attention to details, makes facile the total act, shortens the time, and reduces the extent to which consciousness must concern itself with the process" (Huey, 1908, p. 104). In their influential paper, LaBerge and Samuels (1974) presented a theory of automatic information processing in reading, emphasizing word identification in which the reader progresses through a series of stages in which he learns each subskill component for reading, beginning with an attention demanding the slow process of learning to read a word accurately and progressing to an automatic process where the word is now read fluently and automatically. Accordingly, these researchers proposed two distinct criteria of achievement: accuracy and automaticity (fluency). Of interest, they also emphasize the importance of dependency on attention in determining readiness to advance to the next skill. For example, they indicate accuracy in reading a letter or word alone is insufficient as a criterion for determining readiness for the next step and suggest that the "amount of attention required" be used as part of the criterion for readiness (LaBerge \& Samuels, 1974, p. 319). They posit that once lower level subskills are automatized, attention would then be freed and could be allocated for higher level functions such as semantics and text comprehension.

Since the publication of LaBerge and Samuels' (1974) theory, investigators have sought to describe the characteristics of what is meant by automaticity, and more recently, proceeded to examine the mechanisms underlying automaticity and their relationship to attention and other cognitive processes (Logan, 1988a, 1991; Logan \& Etherton, 1998; Logan, Taylor, \& Etherton, 1996, 1999). Although rooted in LaBerge and Samuel's general theory of automaticity, Logan and colleagues conceptualize a somewhat broader view of automaticity and reading.

Logan summarizes the perceived properties of automatic processes as fast, effortless, autonomous (not reliant on intention), and unconscious (Logan, 1997). Rather than an all or none phenomenon, automatic processes may possess several, but not all of these properties, and possess each in different degrees. In this view, automaticity is a continuum, with more properties developing and developing in greater degrees through practice.

Logan proposes the "instance theory" to conceptualize learning (to read); within this framework, the mechanism is memory, more specifically, episodic memory, with attention featured prominently (Logan, 1988a, 1988b, 1990, 1992, 2002). Instance theory offers three assumptions: obligatory encoding, obligatory retrieval, and instance representation (Logan, 1988a, 1988b, 1990). In the instance theory, attention is critical to obligatory encoding and to obligatory retrieval. Attention to an object is "sufficient to cause it to be encoded into memory," whereas attention to an object is "sufficient to cause things associated with it in the past to be retrieved (Logan, 1997, p. 128).

According to instance theory, with practice, the number of memory traces or representations increases, resulting in increasingly greater ease in retrieval of such instances. It is the change in memory retrieval that is reflected in automatization of the response. Logan contrasts the fast and effortless retrieval characterizing automatic performance with the slow, effortful novice performance necessary when first learning a task. With automaticity there is no longer a dependence on solving the problem; rather, algorithmic multistep performance is shifted to a holistic, rapid retrieval of the memory trace or "instance" of the solution. Thus, the critical requirement for automaticity is for the reader to encode the relevant items in memory and to retrieve them on a subsequent encounter, and for both encoding and retrieval, attention is central.

As discussed, in considering the relation between phonological recoding and attention, a prevalent view holds the generation of the phonological code from print to be modular, which is automatic and not attention demanding, and does not require any other cognitive process. Recent evidence presents a competing view, suggesting that attention is necessary for the computation of phonology resulting in reading the word aloud. The results of a series of experiments designed to test the claim that phonological codes are generated automatically from print led Reynolds and Besner (2006) to conclude 
that mechanisms characterizing the lexical and sublexical components of the dual route addressed phonological recoding and assembled phonological recoding, respectively, rely on and require attention.

The demonstration of the critical role of attention in phonological recoding processes now mandate a closer examination of attention itself and its role in reading as well as an investigation of the possibility that it is the lack or deficiency of attention that plays a causal role in reading difficulties. Much of the focus of recent pedagogy in teaching reading and remediating reading difficulties has centered on teaching children how letters map to sounds. These newer data now suggest that in addition it may be useful to consider the role of attentional mechanisms in support of reading and their disruption as a factor in reading difficulties and also, to begin to consider potential approaches to improving attention in struggling readers. In the remainder of this paper we discuss reading and attention from the perspective of potential neurobiological commonalities that may lead to a deeper understanding of their relationship and the possible impact of one on the other in normal development and in developmental dyslexia.

\section{Definition and Epidemiology}

Prior to discussing newer developments in the neurobiology of reading and dyslexia (here, developmental dyslexia and dyslexia are used interchangeably), basic parameters of the reading disorder, including its definition and epidemiology will be briefly reviewed. Developmental dyslexia reflects an unexpected difficulty in reading in children and adults who appear to have all the factors present (intelligence, motivation, exposure to reasonable reading instruction) that are necessary to turn print into meaning (Shaywitz, 1996, 2003). That is to say, in dyslexic individuals, their reading, especially reading fluency, is below that expected for a person of their level of education, intelligence, or professional status. This notion of an "unexpected" difficulty in reading was reflected in the first report of developmental dyslexia appearing in the literature. The report, titled "A Case of Congenital Word Blindness," recorded the observations of a British physician, W. Pringle Morgan, of his patient Percy F., age 14 years, in the British Medical Journal:

He has always been a bright and intelligent boy, quick at games, and in no way inferior to others his age. His great difficulty has been-and is nowhis inability to read. He has been at school or under tutors since he was 7 years old, and the greatest efforts have been made to teach him to read, but, in spite of this laborious and persistent training, he can only with difficulty spell out words of one syllable...

I might add that the boy is bright and of average intelligence in conversation. His eyes are normal ... and his eyesight is good. The schoolmaster who has taught him for some years says that he would be the smartest lad in the school if the instruction were entirely in oral ... (Morgan, 1896, p. 1378)

In 2008 Percy would be diagnosed with developmental dyslexia. Since Morgan's first description over a century ago, the notion of dyslexia as an unexpected difficulty in reading has endured as parents, educators, clinicians, and investigators continue to become aware, both of the large numbers of individuals affected by the disorder, and also learn more about the basic mechanisms underlying it.

Reflecting accumulating empiric data, a working group provided the following updated definition of developmental dyslexia:

Dyslexia is a specific learning disability that is neurobiological in origin. It is characterized by difficulties with accurate and/or fluent word recognition and poor spelling and decoding abilities. These difficulties typically result from a deficit in the phonological component of language that is often unexpected in relation to other cognitive abilities and the provision of effective classroom instruction ... (Lyon, Shaywitz, \& Shaywitz, 2003, p. 2)

Dyslexia (also referred to as specific reading disability) is a member of the family of learning disabilities; in fact, reading disability is by far the most common learning disability, affecting over $80 \%$ of those identified as learning disabled (Lerner, 1989).

As with other entities, the specific prevalence rate for dyslexia will reflect the particular definition and cut points established as criteria for identification. Data emanating from multiple sources 
indicate that for large segments of the population, reading remains effortful and skilled reading elusive. For example, results of the 2005 National Assessment of Educational Progress indicate 27\% of high school seniors are reading below the most basic levels (minimum level at which a student can demonstrate an understanding of what s/he has read; Grigg, Donahue, \& Dion, 2007) and 36\% of fourth-grade children are reading below basic levels (Perie, Grigg, \& Donahue, 2005). In the Connecticut Longitudinal Study (CLS) sample survey in which each participant was individually assessed, $17.5 \%$ of students were reading below age or ability levels (Shaywitz et al., 1994). The CLS population has been followed continuously since 1983, with yearly individual assessments of cognitive, academic, behavioral, social, and more recently, neurobiological characteristics. Accordingly, these longitudinal data permit examination of issues relating to the developmental course of reading difficulties. These data indicate the persistence and chronicity of reading problems, refuting the notion, long and tightly held, that reading difficulties are outgrown or somehow reflect a developmental lag (Francis, Shaywitz, Stuebing, Shaywitz, \& Fletcher, 1996; Shaywitz et al., 1995). Although persistent, it is important to keep in mind that the expression of the reading difficulty may change with time, so that difficulties with reading accuracy, especially in very bright children, often evolve into relatively accurate, but not fluent, reading.

\section{Functional Magnetic Resonance Imaging (fMRI) in Studies of Reading and Dyslexia}

\section{General considerations}

These advances in understanding the cognitive basis of dyslexia have largely informed and facilitated studies examining the neurobiological underpinnings of reading and dyslexia. The most consistent and replicable data on the location of the neural systems for reading and how they differ in dyslexic readers has come from studies using fMRI. Other functional brain imaging modalities have also been used to study dyslexia (e.g., electrophysiologic methods such as event-related potentials and magnetoencephalography are particularly suited for examining the chronometry or time course of the reading process). fMRI is noninvasive and safe and can be used repeatedly, properties that make it ideal for studying humans, especially children. The signal used to construct MRI images derives from the determination of the blood oxygen level dependent (BOLD) response; the increase in BOLD signal in regions that are activated by a stimulus or task results from the combined effects of increases in the tissue blood flow, volume, and oxygenation, and in cognitive tasks the changes are typically in the order of $1-5 \%$. Details of fMRI are reviewed by Anderson and Gore (1997), Frackowiak et al. (2004), and Jezzard, Matthews, and Smith (2001).

\section{Neural systems for reading}

Data from laboratories around the world indicate that there are a number of interrelated neural systems used in reading, at least two in posterior brain regions as well as distinct and related systems in anterior regions. We refer to "systems" rather than "regions" because each of the areas of the brain (e.g., occipitotemporal) related to reading generally encompasses more than a single brain region (Figure 1).

These systems have been documented by many laboratories using brain imaging studies (e.g., Brambati et al., 2006; Fiebach, Friederici, Muller, \& Cramon, 2002; Gaillard, Balsamo, Ibrahim, Sachs, \& Xu, 2003; Helenius, Tarkiainen, Cornelissen, Hansen, \& Salmelin, 1999; Horwitz, Rumsey, \& Donohue, 1998; Kronbichler et al., 2006; Nakamura, Dehaene, Jobert, Le Bihan, \& Kouider, in press; Nakamura et al., 2006; Paulesu et al., 2001; Rumsey et al., 1992; Salmelin, Service, Kiesila, Uutela, \& Salonen, 1996; Seki et al., 2001; Shaywitz et al., 1998, 2002b, 2003; Temple et al., 2000, 2001; $\mathrm{Xu}$ et al., 2001). As early as 1891, Dejerine suggested that a portion of the posterior brain (which includes the angular gyrus and supramarginal gyrus in the inferior parietal lobule, and the posterior aspect of the superior temporal gyrus) is critical for reading. Since that time, a large literature on acquired inability to read (acquired alexia) describes neuroanatomic lesions in the parietotemporal system as pivotal in mapping the visual percept of the print onto the phonologic structures of the language 


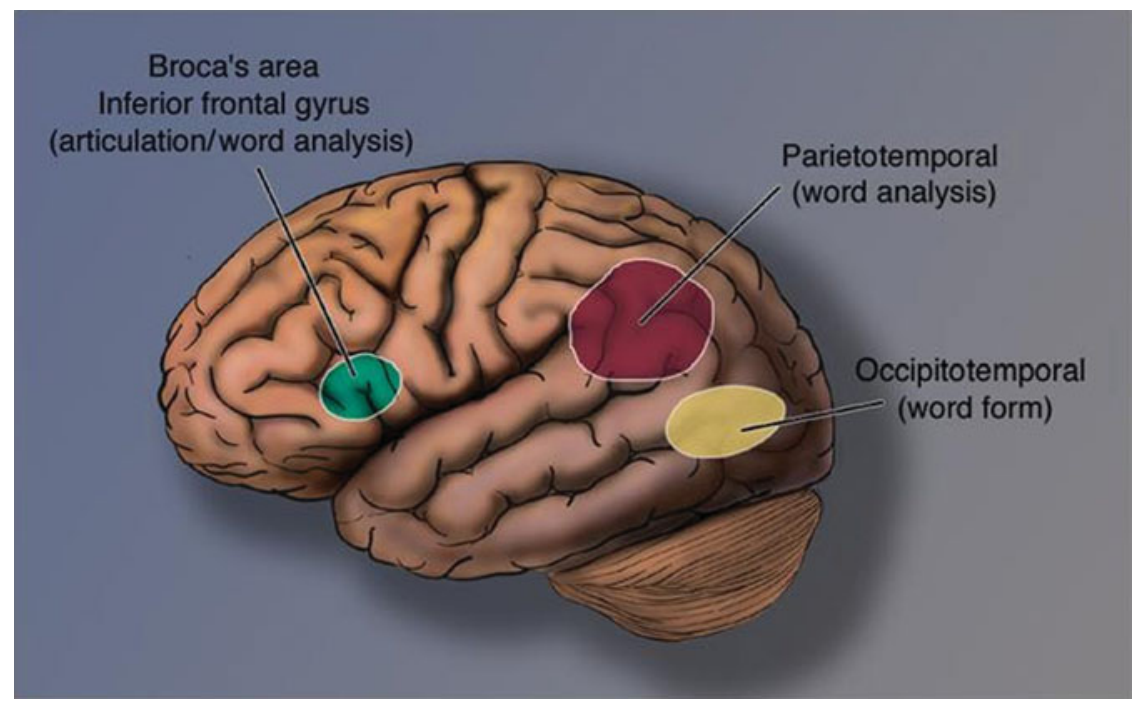

Figure 1. Neural systems for reading. Three neural systems for reading are illustrated for the surface of the left hemisphere: an anterior system in the region of the inferior frontal gyrus (Broca's area), which is believed to serve articulation and word analysis, and two posterior systems, one in the parietotemporal region, which is believed to serve word analysis, and a second in the occipitotemporal region (the word-form area), which is believed to serve for the rapid, automatic, fluent identification of words. Adapted from Overcoming dyslexia: A new and complete science-based program for reading problems at any level, by S. Shaywitz, 2003. New York: Alfred A. Knopf. Copyright 2003 by S. Shaywitz. Adapted with permission.

system (Damasio \& Damasio, 1983; Friedman, Ween, \& Albert, 1993; Geschwind, 1965). Many recent brain imaging studies in patients with developmental dyslexia (see below) have documented the importance of the parietotemporal system in reading, properties involving word analysis, operating on individual units of words (e.g., phonemes). In our figure we refer to the parietotemporal system that encompasses portions of the supramarginal gyrus in the inferior parietal lobule, portions of the posterior aspect of the superior temporal gyrus, and in some studies may even encompass portions of the angular gyrus in the parietal lobe.

A second posterior reading system of particular importance for skilled, fluent reading was first reported by Dejerine in 1892 in association with acquired alexia; since that time acquired alexia resulting from disruption of this system has been demonstrated repeatedly, usually as a result of posterior cerebral artery thrombosis (Binder \& Mohr, 1992; Leff, Spitsyna, Plant, \& Wise, 2006). More recent studies indicate that this second posterior system is localized in the occipitotemporal area, which
Cohen and Dehaene have termed the visual word-form area (VWFA; Cohen et al., 2000; Dehaene, Cohen, Sigman, \& Vinckier, 2005; Dehaene et al., 2001; McCandliss, Cohen, \& Dehaene, 2003; Vinckier et al., 2007). A recent report (Gaillard et al., 2006) provides more convincing cause and effect evidence of the critical role of the VWFA in fluent reading. In this case, a 46-year-old right-handed man developed alexia after resection of a large portion of the posterior brain involving the left inferior occipital/ temporal and the fusiform gyri. Following surgery, reading was slow and inaccurate though other cognitive skills (e.g., object naming, face recognition, language, and writing to dictation) remained normal. Brain activation in the left occipitotemporal system in response to words was normal prior to surgery but was not apparent following resection of the VWFA.

Just how the VWFA functions to integrate phonology (sounds) and orthography (print) is as yet unknown. Some have questioned whether the behavioral effects of lesions of the VWFA are limited to letters and words or if damage to this region results in a more general visual 
processing deficit (Price \& Devlin, 2003, 2004). Starrfelt and Gerlach (2007) find that although activation of the VWFA is greater during word than during picture processing, these differences are attenuated when the picture processing tasks require more elaborate processing. Such findings suggest that activation of the VWFA may not be specific for words " . . . but rather reflects an operation common to word and picture processing that may be differentially affected by task demands." Xue Chen, Jin, and Dong (2006) devised an artificial language and explored the role of the VWFA to acquisition of reading. Their results " . . . suggest that visual familiarity, phonological processing, and semantic processing all make significant but different contributions to shaping the fusiform activation."

Debate continues as to whether visual word recognition takes place serially, in a progressive, step-by-step approach (Dehaene et al., 2005) or conversely, if the left anterior lateral occipitotemporal system functions as an interface between bottom-up visual form information and top-down semantic and phonologic properties in a more dynamic integrative process (McCrory, Mechelli, Frith, \& Price, 2005; Price \& Devlin, 2003). Studies using functional imaging combined with sophisticated task presentations may help to resolve this question (Devlin, Jamison, Gonnerman, \& Matthews, 2006). Patients with alexia compensate for the damage to their VWFA by perceptual tuning of intact right hemisphere homologs in the symmetrical R-VWFA (Cohen et al., 2003, 2004; Henry et al., 2005). Cognitively this reliance on intact neural systems results in the use of both bottom-up and top-down information to decode words. In the case of acquired alexia with damage to the VWFA, alexic patients rely more heavily on intact top-down (semantically based) information in reading (Johnson \& Rayner, 2007).

Another reading-related neural circuit involves an anterior system in the inferior frontal gyrus (Broca's area), a system that has long been associated with articulation and also serves an important function in silent reading and naming (Fiez \& Peterson, 1998; Frackowiak et al., 2004). Most recently, Nakamura et al. (2007) described two additional anterior systems for reading, these in the premotor region: one more dorsal, the other more ventral. We refer to the anterior system as encompassing not only the traditional Broca's area in the left inferior frontal gyrus but also these other systems, that is, the dorsal and ventral premotor regions.

\section{The reading systems in dyslexia in children and adults}

Converging evidence from many laboratories around the world has demonstrated what has been termed "a neural signature for dyslexia," that is, a disruption of posterior reading systems during the reading of real words and pseudowords and often what has been considered as compensatory overactivation in other parts of the reading system (Figure 2).

In a study of children with dyslexia, Shaywitz et al. (2002a) used fMRI to study 144 dyslexic and nonimpaired boys and girls as they read pseudowords and real words. This study was designed to minimize some of the problems encountered in previous studies, and thus examined a large sample, particularly for a functional imaging study. Results indicated that during phonologic analysis, nonimpaired children demonstrate significantly greater activation than do dyslexic children in predominantly left hemisphere sites (representing the anterior reading system around the inferior frontal region, and two posterior sites, one in the parietotemporal system, the other in the occipitotemporal system). Studies in dyslexic children are particularly important because they indicate that dysfunction in left hemisphere posterior reading circuits is already present in dyslexic children and cannot be ascribed simply to a lifetime of poor reading. Further, this study found that, although the posterior reading systems were disrupted in dyslexic readers, compensatory systems developed with an increased activation noted in the left inferior frontal gyrus, activation in the right inferior frontal gyrus, and increased activation in the homolog of the VWFA in the right occipitotemporal area.

It is possible that what is considered compensatory activation in dyslexic readers in the right occipitotemporal area may reflect right-sided activation that is concomitant with activation in nonimpaired readers, although the data remains unclear. Dehaene and associates (Vinckier et al., 2007) indicate that although both the left and right hemisphere occipitotemporal areas are 


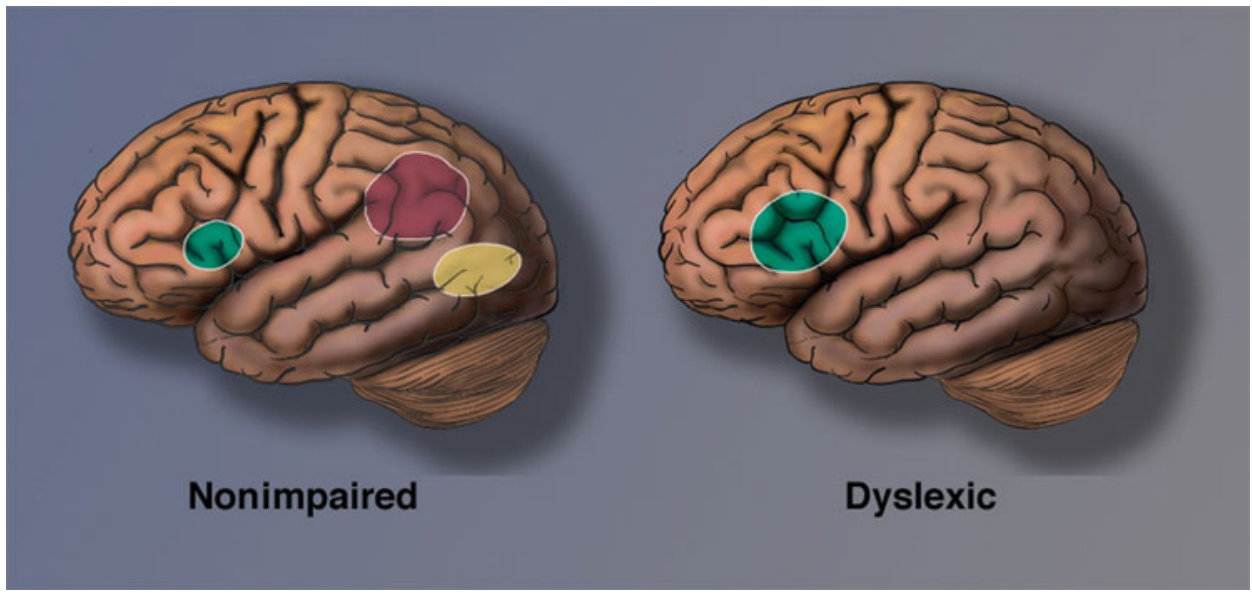

Figure 2. Neural signature for dyslexia. A neural signature for dyslexia is illustrated in this schematic view of left hemisphere brain systems in (left) nonimpaired and (right) dyslexic readers. In nonimpaired readers, the three systems provided in Figure 1 are shown. In dyslexic readers, the anterior system is slightly overactivated compared with systems of nonimpaired readers; in contrast, the two posterior systems are underactivated. This pattern of underactivation in left posterior reading systems is referred to as the neural signature for dyslexia. Adapted from Overcoming dyslexia: A new and complete science-based program for reading problems at any level, by S. Shaywitz, 2003. New York: Alfred A. Knopf. Copyright 2003 by S. Shaywitz. Adapted with permission.

activated during reading, their data indicate that the activations are "asymmetrical in favor of the left hemisphere." Other investigators suggest that both left and right occipitotemporal areas are used in typical reading. For example, in an fMRI study contrasting brain activation of words and pseudowords, Fiebach et al. (2002) found that words produced greater activation in bilateral occipitotemporal and posterior left middle temporal areas. More recently, Ben Shachar, Dougherty, Deutsch, and Wandell (2007) reported increased activation in the VWFA as masked words became more visible, suggesting that both left and right occiptiotemporal areas are important in processing shapes in general, and the visually presented word, in particular.

Whether the occipitotemporal areas in nonimpaired readers are activated bilaterally or primarily in left hemisphere, the data from fMRI studies in children with dyslexia reported by our group converge with reports from many investigators using functional brain imaging, which show a failure of left hemisphere posterior brain systems to function properly during reading (Helenius et al., 1999; Horwitz et al., 1998; Paulesu et al., 2001; Rumsey et al., 1992; Salmelin et al., 1996; Seki et al., 2001; Shaywitz et al., 1998, 2002a, 2003; Temple et al., 2000, 2001). Recent studies report similar findings in German and Italian dyslexic readers. Kronblicher et al. (2006) used sentences and studied dysfluent compared to fluent German readers. Dyslexics demonstrated reduced activation in the left supramarginal gyrus (parietotemporal system) and left occipitotemporal system with compensatory activation in left inferior frontal area. Brambati et al. (2006), studied dyslexic Italian adults with a family history of dyslexia and found reduced activation in dyslexics in posterior reading systems, paralleling results in English-speaking and German-speaking dyslexic readers, and confirming the findings from voxel-based morphometry reported by these investigators previously indicating reductions of gray matter volume in posterior reading systems in bilateral inferior and superior temporal lobe areas in familial dyslexia (Brambati et al., 2004).

Development of reading systems in dyslexia and the importance of the occipitotemporal reading system

Although converging evidence points to three important neural systems for reading, few studies 
have examined age-related changes in these systems in typical readers or in dyslexic children. In a recent report, Shaywitz et al. (2007) used fMRI to study age-related changes in reading in a crosssectional study of 232 dyslexic and nonimpaired boys and girls as they read pseudowords. Findings indicated that the neural systems for reading that develop with age in nonimpaired readers differ from those which develop in dyslexic readers. These findings noted below now permit a more fine-grained analysis of the word-form area by identifying two systems within the greater word form area. Specifically, a system for reading that develops with age in dyslexic readers differs from that in nonimpaired readers, primarily to being a more posterior and medial system, rather than a more anterior and lateral system within the left occipitotemporal area. Of interest, this difference in activation patterns between the two groups of readers has parallels to reported brain activation differences observed during reading of two Japanese writing systems: Kana and Kanji. Left anterior lateral occipitotemporal activation, similar to that seen in nonimpaired readers, occurred during reading Kana (Nakamura, Dehaene, Jobert, Le Bihan, \& Kouider, 2005). Kana script employs symbols that are linked to the sound or phonologic element (comparable to English and other alphabetic scripts). In Kana and in alphabetic scripts, children initially learn to read words by learning how letters and sounds are linked and then, over time, these linkages are integrated and permanently instantiated as a word form. Recall, knowledge of how letters and sounds are linked, allows a reader to sound out and read new words.

In contrast, posterior medial occipitotemporal activation, comparable to that observed in dyslexic readers, was noted during reading of Kanji script (Nakamura et al., 2005). Consideration of the mechanisms used for reading Kanji compared to Kana provide insights into potentially different mechanisms that develop with age in dyslexic contrasted to nonimpaired readers. Kanji script uses ideographs where each character must be memorized suggesting that the posterior medial occipitotemporal system functions as a memory-based system. It is reasonable to suppose that as dyslexic children mature this posterior medial system supports memorization rather than the progressive sound- symbol linkages observed in nonimpaired readers. There is evidence that dyslexic readers are not able to make good use of sound-symbol linkages as they mature, and instead, come to rely on memorized words. For example, phonologic deficits continue to characterize struggling readers even as they enter adolescence and adult life (Bruck, 1992; Shaywitz et al., 1999), and, as described in the next section, persistently poor adult readers read words by memorization so that they are able to read familiar words but have difficulty reading unfamiliar words (Shaywitz et al., 2003).

Thus, these results support and now extend previous findings to indicate that the system responsible for the integration of letters and sounds, the anterior lateral occipitotemporal system, is the neural circuit that develops with age in nonimpaired readers. Conversely, dyslexic readers, who struggle to read new or unfamiliar words, come to rely on an alternate system, the posterior medial occipitotemporal system, that functions via memory networks. The importance of compensatory systems for reading that engage components of the memory system is also shown in a study described below.

\section{Types of reading disabilities}

Shaywitz et al. (2003) examined the neural systems for reading in two groups of young adults who were poor readers as children, a relatively compensated group and a group with persistent reading difficulties, and compared them to nonimpaired readers. In addition, compensated and persistently poor readers were compared to see whether there were any factors distinguishing the compensated from persistently poor readers that might account for their different outcomes. The study took advantage of the availability of a cohort who are participants in the CLS representative sample of now young adults who have been prospectively followed since 1983 when they were age 5 years, and who have had their reading performance assessed yearly throughout their primary and secondary schooling (Ferrer et al., 2007; Shaywitz et al., 1999; Shaywitz, Escobar, Shaywitz, Fletcher, \& Makuch, 1992; Shaywitz, Fletcher, Holahan, \& Shaywitz, 1992; Shaywitz, Shaywitz, Fletcher, \& Escobar, 1990). 
Three groups of young adults were classified as (a) persistently poor readers (PPR), (b) accuracy (but not fluency) improved (compensated) readers (AIR), and (c) nonimpaired readers (NI). Findings during pseudoword rhyming in both groups of poor readers (AIR, PPR) were similar to those observed in previous studies, that is, a relative underactivation in posterior neural systems located in the superior temporal and the occipitotemporal areas. But when reading real words, brain activation patterns in the AIR and PPR readers diverged. As they had for pseudoword reading, compared to NI, AIR (compensated dyslexic readers) demonstrated relative underactivation in left posterior systems. In contrast, during real-word reading PPR subjects activated posterior systems. Thus, we observed (during real-word reading) comparable activation in NI and PPR in the posterior reading systems, findings that were both new and unexpected. Despite the significantly better reading performance in NI compared to PPR on every reading task administered, left posterior reading systems were activated during reading real words in both NI and PPR.

Shaywitz et al. (2003) hypothesized that the PPR readers were reading real words very differently from NI readers, reading the very simple real words primarily by memory. Functional connectivity analysis (in contrast to, e.g., structural connectivity measured by diffusion tensor imaging [DTI]) was used to examine how the skilled reading area in the left occipitotemporal VWFA was connected in NI compared to PPR readers (McIntosh, Bookstein, Haxby, \& Grady, 1996; McIntosh, Nyberg, Bookstein, \& Tulving, 1997). Findings indicated that NI readers demonstrated connectivity between the left occipitotemporal VWFA and the left inferior frontal gyrus, a traditional language region. In contrast, PPR subjects demonstrated functional connectivity between the VWFA and right prefrontal areas often associated with working memory and memory retrieval (Fletcher, Frith, \& Rugg, 1997; MacLeod, Buckner, Miezin, Petersen, \& Raichle, 1998), an observation consistent with the hypothesis that in the persistently poor readers the occipitotemporal system functions as a component of a memory network. This finding, together with the more recent data on the development of reading systems described in the pre- vious section, amplify the importance of memory systems in dyslexic readers.

Insight to some of the factors responsible for compensation on the one hand and persistence on the other comes from an examination of the early childhood measures. The two groups of disabled readers (AIR and PPR) began school with comparable reading skills but with PPR compared to AIR having poorer cognitive ability and tending to attend more disadvantaged schools. These data suggest that the PPR may be doubly disadvantaged in perhaps being exposed to a less rich language environment at home (Hart \& Risley, 1995) and then less effective reading instruction at school. In contrast, the presence of compensatory factors such as stronger $\operatorname{cog}$ nitive ability allowed the AIR to minimize, in part, the consequences of their phonologic deficit so that as adults AIR were indistinguishable from NI on a measure of reading comprehension and a measure of prose literacy. These findings are consonant with a large body of evidence indicating that the impact of dyslexia can be modified by the availability of compensatory resources, for example, semantic knowledge (Snowling, 2000), use of context (Frith \& Snowling, 1983; Nation \& Snowling, 1997), and verbal ability (Torgesen et al., 2001) to compensate for phonologic deficits.

\section{Effects of reading interventions on neural systems for reading}

Given the converging evidence of a disruption of posterior reading systems in dyslexia, an obvious question relates to the plasticity of these neural systems, that is, whether they are malleable and can be changed by an effective reading intervention. Shaywitz et al. (2004) hypothesized that the provision of an evidence-based, phonologically mediated reading intervention would improve reading and the development of the neural systems serving reading. The experimental intervention was structured to help children gain phonological knowledge (develop an awareness of the internal structure of spoken words), and at the same time, develop their understanding of how the orthography represents the phonology.

Two groups of dyslexic readers as well as a control group were studied. One group of dyslexic 
readers received an experimental intervention that provided second and third grade poor readers with $50 \mathrm{~min}$ of daily individual tutoring that was explicit and systematic and focused on helping children understand the alphabetic principle (how letters and combinations of letters represent the small segments of speech known as phonemes) and provided many opportunities to practice applying the letter-sound linkages taught. The other group of dyslexic readers received what the investigators termed "community intervention, "that is, a variety of interventions commonly provided within the school. However, specific, systematic, explicit phonologically based interventions comparable to the experimental intervention were not used in any of reading programs that were provided to the community group. The children were imaged on three occasions: preintervention, immediately postintervention, and 1 year after the intervention was complete.

Children who received the experimental intervention not only improved their reading but also demonstrated an increase in activation in the anterior system as well as in the parietotemporal and occipitotemporal systems, compared to their preintervention brain activation patterns. Other laboratories have also found that an effective reading intervention influences neural systems in the brain in much the same fashion. Thus, the Gabrieli laboratory examined both adults and children with dyslexia who received auditory processing training requiring that subjects respond to a high pitched stimulus. Following 33 training days, subjects demonstrated not only improvement on both rapid auditory processing and auditory language comprehension but also greater activation in the left prefrontal cortex (PFC) after training compared to before training (Temple et al., 2000). In a study of children with dyslexia, the same intervention resulted in improvement in reading accuracy and increased brain activation in the posterior reading systems as well as in right hemisphere and cingulate cortex (Temple et al., 2003). Richards et al. (2000) used proton MR spectroscopy to measure brain lactate concentrations at two time points, 1 year apart, in dyslexic and control boys before and after 3 weeks of a phonologically based reading intervention. Measuring lactate is a direct measure of brain metabolism, with lower levels pre- sumably reflecting more efficient metabolism. Before treatment dyslexic boys demonstrated increased lactate concentration (compared to controls) in the left anterior quadrant during a phonologic task. After treatment, brain lactate concentrations were no different in the dyslexic and control boys, and reading improved after treatment, presumably reflecting an improvement in the efficiency of brain function after the intervention. This same investigative group reported fMRI changes in posterior reading areas following $28 \mathrm{hr}$ of an intensive phonological and morphological reading intervention (Aylward et al., 2003). Using a phonologically based intervention consisting of 3-hr daily sessions for 8 weeks, Eden et al. (2004) compared adults who had been diagnosed as dyslexic as children to adults who did not receive the intervention. Although real word reading did not improve, tests of phonemic awareness did improve, and posterior brain systems in left hemisphere (as well as right hemisphere homologs) increased in activation compared to the preintervention imaging.

In summary, these data demonstrate that an intensive evidence-based reading intervention brings about significant changes in brain organization so that brain activation patterns resemble those of typical readers. These data have important implications for public policy regarding teaching children to read: The provision of an evidencebased reading intervention at an early age improves reading and facilitates the development of those neural systems that underlie reading. Further studies are necessary to clarify the long-term impact of these interventions, particularly on the development of fluency, and the neural systems serving fluent reading.

\section{Neurobiological Mechanisms in Attention}

In previous sections, we discussed the cognitive theories of reading and dyslexia, indicating that an account of the contribution of attentional mechanisms are critical to a full understanding of the reading process. The neurobiology of reading was reviewed, so we now turn our attention to neurobiological mechanisms in attention. Considerable evidence from a number of lines of investigation points to (a) the role of higher association cortices, particularly the PFC, and (b) the role of catecholaminergic systems 
in attentional mechanisms. In general, higher order sensory cortices, such as the inferior temporal cortex, influence attentional mechanisms by focusing on particular details; the posterior parietal cortex also plays a role in attention, presumably by allocating attentional resources via connections with the PFC. It is the PFC that has long been suspected of regulating attention by inhibiting irrelevant stimuli as well as sustaining attention and dividing attention (reviewed in Arnsten, 2006a).

\section{Catecholaminergic systems in attention}

Extensive research links catecholaminergic mechanisms to the cortical and subcortical neural systems serving attention. Subcortical systems in basal ganglia have long been linked to catecholaminergic, primarily dopaminergic, systems and studies that are nearly 30 years old link catecholaminergic mechanisms to the PFC (Brozoski, Brown, Rosvold, \& Goldman, 1979). More recent studies (reviewed in Arnsten, 2006a) elaborate on the role of dopamine on PFC. These studies indicate that stimulation of D1 receptors in PFC produce an inverted U-shaped dose response, with modest levels of D1 stimulation important for normal PFC function, whereas greater stimulation of these same receptors impair attentional and memory systems in the PFC.

Noradrenergic mechanisms also appear to play an important role in attentional mechanisms. Noradrenergic neurons arise from brain stem nuclei within the locus coeruleus and project to widespread cortical regions, including the PFC (Ramos \& Arnsten, 2007). Norepinephrine stimulates three types of postsynaptic receptors, and stimulation of each receptor results in somewhat different actions on attentional mechanisms. For example, PFC function is improved by stimulation of a2a receptors with agents such as the a2a agonist guanfacine. In contrast, stimulation of al receptors (by agonists such as phenylephrine) and b1 receptors (by agonists such as betaxalol) impairs PFC function (Birnbaum, Gobeske, Auerbach, Taylor, \& Arnsten, 1999; Birnbaum et al., 2004). Studies in animal models of attention indicate that administration of stimulant medications (methylphenidate, $d$ amphetamine, atomoxetine) result in not only in- creased release of dopamine in basal ganglia but also pronounced effects in the PFC, with high levels of norepinephrine release and significant but lower levels of dopamine release (Bymaster et al., 2002).

Stimulants such as $d$-amphetamine, methylphenidate, and atomoxetine have long been known to affect attention in the clinical syndrome of ADHD. This new understanding of catecholaminergic actions in the brain led Arnsten (2006b) to note that $d$-amphetamine and methylphenidate affect catecholaminergic systems in the brain and that newer agents such as "... atomoxetine (Strattera) also increases norepinephrine and dopamine release in the prefrontal cortex ...," suggesting "that catecholamine release in the prefrontal cortex may be a common action for many ADHD therapeutics" (Arnsten, 2006b, p. 2). Stimulants have also been found to improve other prefrontal cognitive functions such as spatial working memory, response inhibition, and set shifting in "normal" college students (Elliott et al., 1997; Mehta et al., 2000) and in children and adults with ADHD (Aron, Dowson, Sahakian, \& Robbins, 2003; Bedard, Jain, Johnson, \& Tannock, 2007; McInnes, Bedard, Hogg-Johnson, \& Tannock, 2007; Mehta, Goodyer, \& Sahakian, 2004). Further support for the role of noradrenergic mechanisms in general (and presumably their effects on the PFC) come from genetic studies. Thus, in addition to associations among ADHD and the genes encoding for the dopamine transporter and the D1, D4, and D5 receptors, genes related to noradrenergic mechanisms (dopamine beta hydroxylase; gene encoding for the a2A adrenoceptor) have been associated with ADHD (Park et al., 2005; Roman et al., 2003).

\section{Structural MRI and fMRI studies of attentional mechanisms in ADHD}

Structural MRI studies, particularly a recent meta-analysis (Valera, Faraone, Murray, \& Seidman, 2007), have shown a reduction in volume in a number of brain regions in patients with ADHD including the caudate, cerebellar vermis, and corpus callosum, as well as the prefrontal and frontal lobes. A longitudinal structural MRI study (Shaw et al., 2006) suggests that these 
neuranatomical abnormalities are present early in childhood. Specifically, children with ADHD exhibited thinning of the cerebral cortex, particularly over the medial and superior prefrontal and precentral regions, with those with worse clinical outcome having a thinner left medial PFC at baseline. There was also a suggestion that normalization of cortical thickness over the 5 -year period of follow-up occurred only in the better outcome group.

fMRI studies of ADHD have demonstrated dysfunction in multiple neural systems including those in the prefrontal and frontal cortex, caudate nucleus, cerebellum, and parietal cortex (reviewed in Bush, Valera, \& Seidman, 2005; Casey, Nigg, \& Durston, 2007; Epstein et al., 2007). These systems have been demonstrated during tasks tapping cognitive control, including the go/no-go (Durston et al., 2007; Epstein et al., 2007), stop signal tasks, and Stroop tasks (Bush et al., 1999). In general, children with ADHD exhibit hypoactivation of these regions compared to controls, and this hypoactivation has been shown to normalize with stimulant medication (Epstein et al., 2007; Shafritz, Marchione, Gore, Shaywitz, \& Shaywitz, 2004; Vaidya et al., 1998). Most recently, DTI has been used to demonstrate disruption of frontostriatal white matter tracts in children with ADHD (Casey et al., 2007).

\section{Importance of the parietotemporal reading system in developmental dyslexia: A potential link to attentional mechanisms serving reading}

A potential neural mechanism that may help better understand the role of attentional processes in dyslexia comes from studies demonstrating that the posterior parietal cortex appears to play an important role in attention, presumably via connections between the posterior parietal cortex and PFC. Good evidence suggests that competing stimuli result in activation of this parietal-prefrontal pathway, essentially a top-down biasing of attention in favor of one stimulus over another. At the same time, many studies have implicated the left parietal cortex in reading and dyslexia. For example, in two studies, one involving whether two words rhymed (Cao, Bi$\tan$, Chou, Burman, \& Booth, 2006) and one in- volving whether two real words were related (Booth, Bebko, Burman, \& Bitan, 2007), children with dyslexia exhibited reduced activation in a left hemisphere network involving the inferior parietal lobule. These studies are consistent with previous studies in dyslexic children (Shaywitz et al., 2002; Temple et al., 2001) and consistent with studies showing that the inferior parietal lobule is implicated in mapping between orthographic and phonological representations (Booth et al., 2002, 2003; Nakamura et al., 2006, in press; Price, Moore, \& Frackowiak, 1996; Xu et al., 2001). The inferior parietal lobule is also activated during listening comprehension, perhaps representing an indirect route to speech processing (Schmithorst \& Holland, 2006, 2007).

An accumulating literature has begun to emphasize the relationship linking attention, the inferior parietal cortex, and reading. As discussed in the previous section, the inferior parietal lobule is involved in and and plays a significant role in attentional mechanisms. One important piece of evidence comes from a study of a patient with bilateral parietal atrophy, a syndrome known as Balint syndrome (Vinckier et al., 2006). Through an accident of nature, this unfortunate woman was left with a dysfunctional parietal component of the reading pathways but an intact occipitotemporal reading system. Evidence of parietal system influence on reading was demonstrated when geometric features of the display were altered; for example, if words were rotated, letters were separated by double spaces or words were written in mirror reversal. Thus, depending on these critical geometric features (rotation angle, letter spacing, mirror reversal, tasks that seem to tap the parietal system), the patient switched from a good reading performance (when words were displayed normally engaging her intact ventral pathway) to severely impaired reading, when the task required parietal systems.

Perhaps the strongest evidence linking attention, the inferior parietal cortex and reading comes from a study by Nakamura et al. (2005), involving the combined use of visual masking and the disruption of specific components of the reading system by transcranial magnetic stimulation. Using this paradigm, Nakamura et al.'s (2005) findings suggest that a 
more dorsally placed neural system involving the left hemisphere inferior parietal lobule and premotor cortex are involved in print to sound conversion, consistent with much previous data. This system links to word recognition systems in the occipitotemporal cortex. A more ventral system, involving the occipitotemporal, middle temporal, and premotor cortex are involved in lexical decision. This is consistent with many previous studies described earlier. These systems may be the neural correlates of the dual route to reading discussed earlier. What is new is that Nakamura postulates that attentional systems in the PFC act to activate the more dorsal system: “ . . . because brain activation triggered by the conscious perception of wordlike stimuli should be subject to the top-down attentional amplification by the prefrontal cortex. This, in turn, produces a distributed activation of the fronto-temporo-parietal network, ..." This is significant and suggests an alternative intervention strategy for reading, a strategy that focuses on activating prefrontal attentional systems (presumably noradrenergic) that then activate the posterior reading systems.

\section{Catecholaminergic systems and reading}

Of particular interest to studies of reading are reports indicating that stimulants may have beneficial effects on reading in children with both ADHD and dyslexia (Grizenko, Bhat, Schwartz, Ter-Sttepanian, \& Joober, 2006; Keulers et al., 2007; Richardson, Kupietz, Winsberg, Maitinsky, \& Mendell, 1988). Pharmacological studies using stimulants that presumably stimulate prefrontal catecholaminergic systems (noradrenergic and dopaminergic) suggest improvement in reading in dyslexic children, perhaps by the mechanism proposed by Nakamura et al. (2005). This seems to be a promising strategy for further exploration, particularly in view of the great difficulty in finding interventions that improve reading fluency.

\section{Summary and Future Directions}

Recent technological and conceptual advances offer the hope of understanding reading and reading disabilities at a level that could not have been imagined even a decade ago. As noted above, converging evidence from laboratories around the world now demonstrates a neural signature for dyslexia, specifically, a disruption of posterior neural systems serving reading. Such a demonstration provides unequivocal evidence that what was once a hidden disability is real. Furthermore, these fMRI studies now indicate the neural basis for the accommodation of extra time provided on standardized tests to dyslexic students: a disruption of posterior systems for skilled reading, with the development of compensatory ancillary pathways anteriorly and in the right hemisphere. As shown in Figure 3, in contrast to typical readers, dyslexic readers demonstrate a disruption of posterior reading systems in the left parietotemporal and occipitotemporal areas, but appear to develop compensatory systems in left anterior and right anterior areas and the right hemisphere homolog of the left hemisphere VWFA. These ancillary systems allow the dyslexic reader to decode words, but slowly and not automatically. This lack of automatic, fluent reading means that the dyslexic reader may be able to decode words, but is still not able to read quickly and continues to be at a disadvantage compared to nondyslexic peers when taking high-stakes standardized tests such as SATs, Graduate Management Admission Test, Graduate Record Examination, and so forth. However, we caution, as did Bush et al. (2005) in discussing neuroimaging of ADHD, that the neural signature of dyslexia using fMRI has been demonstrated in studies of groups of disabled readers while neuroimaging in individual subjects to date has not proven sensitive enough as a either a biomarker for dyslexia or as a measure of therapeutic effect.

For almost two decades, the central dogma in reading research has been that the generation of the phonological code from print is modular, that is, automatic and not attention demanding and not requiring any other cognitive process. Recent findings now present a competing view, suggesting that attentional mechanisms play a critical role in reading and that disruption of these attentional mechanisms plays a causal role in reading difficulties.

The recognition of the role of attention in reading leads to perhaps the most exciting new development on the horizon: the potential use of pharmacologic agents that may serve as a pharmacologic probe to begin to understand 


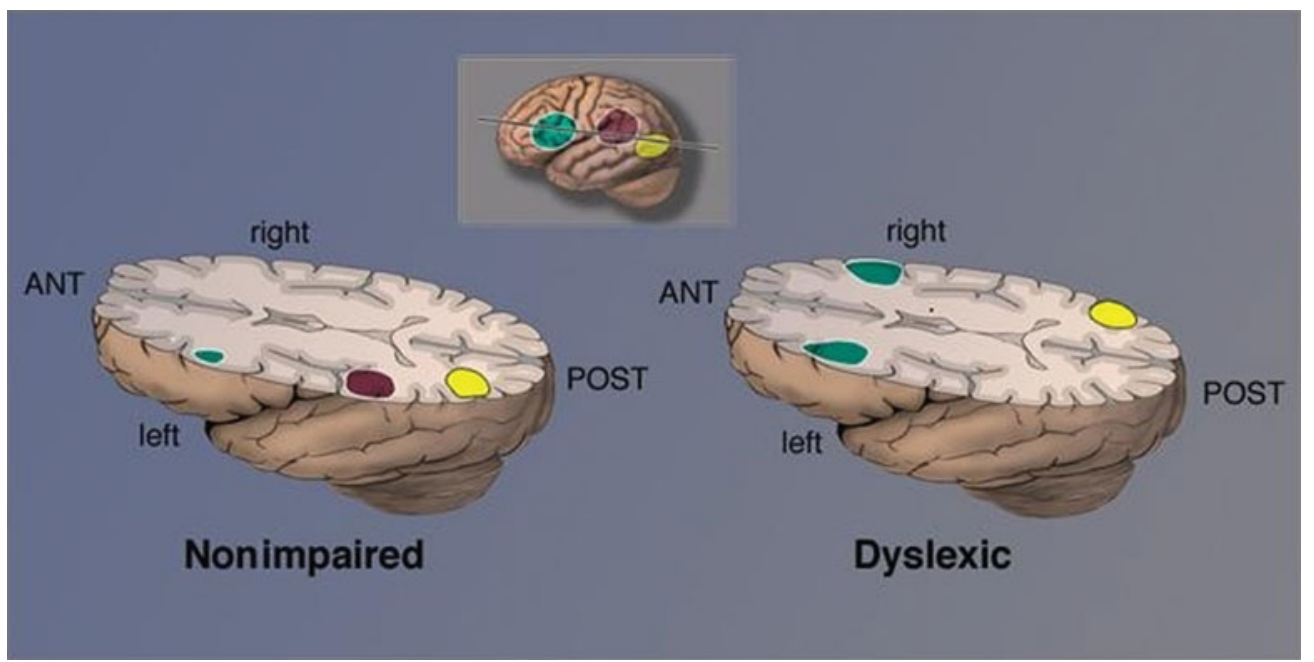

Figure 3. Compensatory neural systems and the neural basis for the requirement for extended time for dyslexic students on high stakes testing. The image is a cutaway view of the brain showing the left and right hemispheres. Nonimpaired readers activate three left hemisphere neural systems for reading: an anterior system and two posterior systems. Dyslexic readers have a disruption in the left hemisphere posterior neural systems for reading but compensate by developing anterior systems in the left and right hemispheres and the posterior homolog of the visual word form area in the right hemisphere. Adapted from Overcoming dyslexia: A new and complete science-based program for reading problems at any level, by S. Shaywitz, 2003. New York: Alfred A. Knopf. Copyright 2003 by S. Shaywitz. Adapted with permission.

the neurochemical mechanisms of reading and dyslexia and their relationship to those mechanisms in ADHD. In particular, the contrast between agents primarily effective on dopaminergic striatal systems (methylphenidate, $d$-amphetamine) and those more selective on noradrenergic systems (atomexetine, guafecine) may provide a window into the neurochemical mechanisms underlying dyslexia as well as potential new avenues for intervention.

\section{References}

Anderson, A., \& Gore, J. (1997). The physical basis of neuroimaging techniques. In M. Lewis \& B. Peterson (Eds.), Child and adolescent psychiatric clinics of North America (Vol. 6, pp. 213-264). Philadelphia, PA: W.B. Saunders.

Arnsten, A. (2006a). Fundamentals of attention-deficit/hyperactivity disorder: Circuits and pathways. Journal of Clinical Psychiatry, 67(Suppl. 8), 7-12.

Arnsten, A. F. T. (2006b). Stimulants: Therapeutic actions in ADHD. Neuropsychopharmacology, 1-8.

Aron, A. R., Dowson, J. H., Sahakian, B. J., \& Robbins, T. W. (2003). Methylphenidate improves response inhibition in adults with attention-deficit/hyperactivity disorder. Biological Psychiatry, 54, 1465-1468.

August, G. J., \& Garfinkel, B. D. (1990). Comorbidity of ADHD and reading disability among clinic-referred children. Journal of Abnormal Child Psychology, 18, 29-45.

Aylward, E., Richards, T., Berninger, V., Nagy, W., Field, K., Grimme, A., et al. (2003). Instructional treatment associated with changes in brain activation in children with dyslexia. Neurology, 61, 212-219.
Bedard, A.-C., Jain, U., Johnson, S. H., \& Tannock, R (2007). Effects of methylphenidate on working memory components: Influence of measurement. Journal of Child Psychology and Psychiatry and Allied Disciplines, 48, 872-880.

Ben-Shachar, M., Dougherty, R. F., Deutsch, G. K., \& Wandell, B. A. (2007). Differential sensitivity to words and shapes in ventral occipito-temporal cortex. Cerebral Cortex, 17, 1604-1611.

Binder, J., \& Mohr, J. (1992). The topography of callosal reading pathways. Brain, 115, 1807-1826.

Birnbaum, S. G., Gobeske, K. T., Auerbach, J., Taylor, J., \& Arnsten, A. F. T. (1999). A role for norepinephrine in stress-induced cognitive deficits: Alpha 1-adrenoceptor mediation in prefrontal cortex. Biological Psychiatry, 46, 1266-1274.

Birnbaum, S. G., Yuan, P. X., Wang, M., Vijayraghavan, S., Bloom, A. K., Davis, D. J., et al. (2004). Protein kinase C overactivity impairs prefrontal cortical regulation of working memory. Science, 306, 882-884.

Bloomfield, L. (1933). Language. New York: Holt, Rinehart and Winston. 
Booth, J. R., Bebko, G., Burman, D. D., \& Bitan, T. (2007). Children with reading disorder show modality independent brain abnormalities during semantic tasks. Neuropsychologia, 45, 775-783.

Booth, J. R., Burman, D. D., Meyer, J. R., Gitelman, D. R., Parrish, T. B., \& Mesulam, M. M. (2002). Functional anatomy of intra- and cross-modal lexical tasks. NeuroImage, 16, 7-22.

Booth, J. R., Burman, D. D., Meyer, J. R., Gitelman, D. R., Parrish, T. B., \& Mesulam, M. M. (2003). Relation between brain activation and lexical performance. Human Brain Mapping, 19, 155-169.

Brambati, S., Termine, C., Ruffino, M., Danna, M., Lanzi, G., Stella, G., et al. (2006). Neuropsychological deficits and neural dysfunction in familial dyslexia. Brain Research, 1113, 174-185.

Brambati, S. M., Termine, C., Ruffino, M., Stella, G., Fazio, F., Cappa, S. F., et al. (2004). Regional reductions of gray matter volume in familial dyslexia. Neurology, 63, 742-745.

Brozoski, T., Brown, R., Rosvold, H., \& Goldman, P. (1979). Cognitive deficit caused by regional depletion of dopamine in prefrontal cortex of rhesus monkey. Science, 205, 929-931.

Bruck, M. (1992). Persistence of dyslexics' phonological awareness deficits. Developmental Psychology, 28, 874-886.

Bruck, M. (1998). Outcomes of adults with childhood histories of dyslexia. In C. Hulme \& R. Joshi (Eds.), Cognitive and linguistic bases of reading, writing, and spelling (pp. 179-200). Mahwah, NJ: Erlbaum.

Bush, G., Frazier, J. A., Rauch, S. L., Seidman, L. J., Whalen, P. J., Jenike, M. A., et al. (1999). Anterior cingulate cortex dysfunction in attention-deficit/hyperactivity disorder revealed by fMRI and the counting Stroop. Biological Psychiatry, 45, 1542-1552.

Bush, G., Valera, E., \& Seidman, L. (2005). Functional neuroimaging of attention-deficit/hyperactivity disorder: A review and suggested future directions. Biological Psychiatry, 57, 1273-1284.

Bymaster, F., Katner, B., Nelson, D., Hemrick-Luecke, S., Threlkeld, P., Heiligenstein, J., et al. (2002). Atomoxetine increases extracellular levels of norepinephrine and dopamine in prefrontal cortex of rat: A potential mechanism for efficacy in attention deficit/hyperactivity disorder. Neuropsychopharmacology, 27, 699-711.

Cao, F., Bitan, T., Chou, T.-L., Burman, D. D., \& Booth, J. R. (2006). Deficient orthographic and phonological representations in children with dyslexia revealed by brain activation patterns. Journal of Child Psychology and Psychiatry and Allied Disciplines, 47, 1041-1050.

Casey, B., Nigg, J., \& Durston, S. (2007). New potential leads in the biology and treatment of attention deficithyperactivity disorder. Current Opinion in Neurology, 20, 119-124.

Casey, B. J., Epstein, J. N., Buhle, J., Liston, C., Davidson, M. C., Tonev, S. T., et al. (2007). Frontostriatal connectivity and its role in cognitive control in parent-child dyads with ADHD. American Journal of Psychiatry, 164, 1729-1736.

Cohen, L., Dehaene, S., Naccache, L., Lehericy, S., Dehaene-Lambertz, G., Henaff, M. A., et al. (2000). The visual word form area: Spatial and temporal characterization of an initial stage of reading in normal subjects and posterior split-brain patients. Brain, 123(Pt. 2), 291-307.

Cohen, L., Lehericy, S., Henry, C., Bourgeois, M., Larroque, C., Sainte-Rose, C., et al. (2004). Learning to read without a left occipital lobe: Right-hemispheric shift of visual word form area. Annals of Neurology, 56, 890-894.

Cohen, L., Martinaud, O., Lemer, C., Lehericy, S., Samson, Y., Obadia, M., et al. (2003). Visual word recognition in the left and right hemispheres: Anatomical and functional correlates of peripheral alexias. Cerebral Cortex, 13, 1313-1333.

Coltheart, M. (1978). Lexical access in simple reading tasks. In G. Underwood (Ed.) Strategies of information processing (pp. 151-216). London: Academic Press.

Coltheart, M. (1985). Cognitive neuropsychology and the study of reading. In M. Posner \& O. Marin (Eds.), Attention and performance X1 (pp. 3-37). Hillsdale, NJ: Erlbaum.

Coltheart, M., Curtis, B., Atkins, P., \& Haller, M. (1993) Models of reading aloud: Dual-route and paralleldistributed-processing approaches. Psychological Review, 100, 589-608.

Coltheart, M., \& Rastle, K. (1994). Serial processing in reading aloud: Evidence for dual-route models of reading. Journal of Experimental Psychology: Human Perception and Performance, 20, 1197-1211.

Coltheart, M., Rastle, K., Perry, C., Langdon, R., \& Ziegler, J. (2001). DRC: A dual route cascaded model of visual word recognition and reading aloud. Psychological Review, 108, 204-256.

Damasio, A. R., \& Damasio, H. (1983). The anatomic basis of pure alexia. Neurology, 33, 1573-1583.

Dehaene, S., Cohen, L., Sigman, M., \& Vinckier, F. (2005). The neural code for written words: A proposal. Trends in Cognitive Sciences, 9, 335-341.

Dehaene, S., Naccache, L., Cohen, L., Le Bihan, D., Mangin, J., Poline, J., et al. (2001). Cerebral mechanisms of word masking and unconscious repetition priming. $\mathrm{Na}$ ture Neuroscience, 4, 752-758.

Dejerine, J. (1891). Sur un cas de cécité verbale avec agraphie, suivi d'autopsie. Compte Rendu des Seances Société du Biologie, 43, 197-201.

Dejerine, J. (1892). Contribution a l'etude anatomo-pathologique et clinique des differentes varietes de cecite verbale. Memoires de la Societe de Biologie, 4, 61-90.

Devlin, J., Jamison, H., Gonnerman, L., \& Matthews, P. (2006). The role of the posterior fusiform gyrus in reading. Journal of Cognitive Neuroscience, 18, 911-922.

Durston, S., Davidson, M. C., Mulder, M. J., Spicer, J. A., Galvan, A., Tottenham, N., et al. (2007). Neural and behavioral correlates of expectancy violations in attentiondeficit hyperactivity disorder. Journal of Child Psychology and Psychiatry, 48, 881-889.

Dykman, R. A., \& Ackerman, P. T. (1991). Attention deficit disorder and specific reading disability: Separate but often overlapping disorders. Journal of Learning Disabilities, 24, 96-103.

Eden, G., Jones, K., Cappell, K., Gareau, L., Wood, F., Zeffiro, T., et al. (2004). Neural changes following remediation in adult developmental dyslexia. Neuron, 44 411-422.

Elliott, R., Sahakian, B., Matthews, K., Bannerjea, A., Rimmer, J., \& Robbins, T. (1997). Effects of methylphenidate on spatial working memory and planning in healthy young adults. Psychopharmacology, 131, 196-206.

Epstein, J. N., Casey, B. J., Tonev, S. T., Davidson, M. C., Reiss, A. L., Garrett, A., et al. (2007). ADHD- and medication-related brain activation effects in concordantly affected parent-child dyads with ADHD. Journal of Child Psychology and Psychiatry, 48, 899-913.

Ferrer, E., McArdle, J., Shaywitz, B., Holahan, J., Marchione, K., \& Shaywitz, S. (2007). Longitudinal models 
of developmental dynamics between reading and cognition from childhood to adolescence. Developmental Psychology, 43, 1460-1473.

Fiebach, C. J., Friederici, A. D., Muller, K., \& Cramon, D. Y. V. (2002). fMRI evidence for dual routes to the mental lexicon in visual word recognition. Journal of Cognitive Neuroscience, 14, 11-23.

Fiez, J. A., \& Peterson, S. E. (1998). Neuroimaging studies of word reading. Proceedings of the National Academy of Science of the United States of America, 95, 914-921.

Fletcher, P., Frith, C., \& Rugg, M. (1997). The functional anatomy of episodic memory. Trends in Neuroscience, 20, 213-218.

Fodor, J. A. (1983). The modularity of mind. Cambridge, MA: MIT Press.

Forster, K. I., \& Chambers, S. M. (1973). Lexical access and naming time. Journal of Verbal Learning and Verbal Behavior, 12, 627-635.

Frackowiak, R., Friston, K., Frith, C., Dolan, R., Price, C., Zeki, S., et al. (2004). Human Brain Function (2nd ed.). San Diego, CA: Academic Press/Elsevier Science.

Francis, D. J., Shaywitz, S. E., Stuebing, K. K., Shaywitz, B. A., \& Fletcher, J. M. (1996). Developmental lag versus deficit models of reading disability: A longitudinal, individual growth curves analysis. Journal of Educational Psychology, 88, 3-17.

Friedman, R. F., Ween, J. E., \& Albert, M. L. (1993). Alexia. In K. M. Heilman \& E. Valenstein (Eds.), Clinical neuropsychology (3rd ed., pp. 37-62). New York: Oxford University Press.

Frith, U., \& Snowling, M. (1983). Reading for meaning and reading for sound in autistic and dyslexic children. British Journal of Developmental Psychology, 1, 329-342.

Gaillard, R., Naccache, L., Pinel, P., Clemenceau, S., Volle, E., Hasboun, D., et al. (2006). Direct intracranial, FMRI, and lesion evidence for the causal role of left inferotemporal cortex in reading. Neuron, 50, 191-204.

Gaillard, W. D., Balsamo, L. M., Ibrahim, Z., Sachs, B. C., $\&$ Xu, B. (2003). fMRI identifies regional specialization of neural networks for reading in young children. $\mathrm{Neu}$ rology, 60, 94-100.

Galaburda, A. M., Menard, M., \& Rosen, G. D. (1994). Evidence for aberrant auditory anatomy in developmental dyslexia. Proceedings of the National Academy of Sciences of the United States of America, 91, 8010-8013.

Geschwind, N. (1965). Disconnection syndromes in animals and man. Brain, 88, 237-294.

Grigg, W., Donahue, P., \& Dion, G. (2007). The Nation's Report Card: 12th-grade reading and mathematics 2005 (NCES Report 2007-468). Washington, DC: US Government Printing Office.

Grizenko, N., Bhat, M., Schwartz, G., Ter-Sttepanian, M., \& Joober, R. (2006). Efficacy of methylphenidate in children with attention-deficit hyperactivity disorder and learning disabilitites: A randomized crossover trial. Journal of Psychiatry \& Neuroscience, 31, 46-51.

Gronau, N., \& Frost, R. (1997). Prelexical phonologic computation in a deep orthography: Evidence from backward masking in Hebrew. Psychonomic Bulletin \& Review, 4, 107-112.

Harris, M., \& Coltheart, M. (1986). Language processing in children and adults: An introduction. London: Routledge \& Kegan Paul.

Hart, B. H., \& Risley, T. R. (1995). Meaningful differences in the everyday experience of young American children. Baltimore, MD: Paul H. Brookes.

Helenius, P., Tarkiainen, A., Cornelissen, P., Hansen, P. C., \& Salmelin, R. (1999). Dissociation of normal feature analysis and deficient processing of letter-strings in dyslexic adults. Cerebral Cortex, 4, 476-483.

Henry, C., Gaillard, R., Volle, E., Chiras, J., Ferrieux, S., Dehaene, S., et al. (2005). Brain activations during letter-by-letter reading: A follow-up study. Neuropsychologia, 43, 1983-1989.

Horwitz, B., Rumsey, J. M., \& Donohue, B. C. (1998). Functional connectivity of the angular gyrus in normal reading and dyslexia. Proceedings of the National Academy of Science of the United States of America, 95, 8939-8944

Huey, E. (1908). The psychology and pedagogy of reading. New York: Macmillan.

Hulme, C., Snowling, M., Caravolas, M., \& Carroll, J. (2005). Phonological skills are (probably) one cause of success in learning to read: A comment on Castles and Coltheart. Scientific Studies of Reading, 9, 351-365.

Jezzard, P., Matthews, P., \& Smith, S. (2001). Functional MRI, an introduction to methods. Oxford: Oxford University Press.

Johnson, R. L., \& Rayner, K. (2007). Top-down and bottom-up effects in pure alexia: Evidence from eye movements. Neuropsychologia, 45, 2246-2257.

Johnston, M., \& Castles, A. (2003). Dissociating automatic orthographic and phonological codes in lexical access and lexical acquisition. In S. Kinoshita \& S. Lupker (Eds.), Masked priming: The state of the art (pp. 193-222). Hove: Psychology Press.

Keulers, E. H. H., Hendriksen, J. G. M., Feron, F. J. M., Wassenberg, R., Wuisman-Frerker, M. G. F., Jolles, J., et al. (2007). Methylphenidate improves reading performance in children with attention deficit hyperactivity disorder and comorbid dyslexia: An unblinded clinical trial. European Journal of Paediatric Neurology, 11, 21-28.

Kronbichler, M., Hutzler, F., Staffen, W., Mair, A., Ladurner, G., \& Wimmer, H. (2006). Evidence for a dysfunction of left posterior reading areas in German dyslexic readers. Neuropsychologia, 44, 1822-1832.

LaBerge, D., \& Samuels, S. J. (1974). Toward a theory of automatic information processing in reading. Cognitive Psychology, 6, 293-323.

Lawler, A. (2001). Archaeology. Writing gets a rewrite. Science, 292, 2418-2420.

Leff, A., Spitsyna, G., Plant, G., \& Wise, R. (2006). Structural anatomy of pure and hemianopic alexia. Journal of Neurology, Neurosurgery and Psychiatry, 77, 1004-1007.

Lefly, D. L., \& Pennington, B. F. (1991). Spelling errors and reading fluency in compensated adult dyslexics. Annals of Dyslexia, 41, 143-162.

Lerner, J. (1989). Educational interventions in learning disabilities. Journal of the American Academy of Child \& Adolescent Psychiatry, 28, 326-331.

Liberman, A., Cooper, F., Shankweiler, D., \& StuddertKennedy, M. (1967). Perception of the speech code. Psychological Review, 74, 431-461.

Liberman, I. Y., Shankweiler, D., \& Liberman, A. M. (1989). Phonology and reading disability: Solving the reading puzzle. In D. Shankweiler \& I. Y. Liberman (Eds.), International Academy for Research in Learning Disabilities monograph series (Vol. 6, pp. 1-33). Ann Arbor, MI: University of Michigan Press.

Livingstone, M. S., Rosen, G. D., Drislane, F. W., \& Galaburda, A. M. (1991). Physiological and anatomical evidence for a magnocellular defect in developmental dyslexia. Proceedings of the National Academy of Sciences of the United States of America, 88, 7943-7947. 
Logan, G. (1988a). Toward an instance theory of automatization. Psychological Review, 95, 492-527.

Logan, G. (1988b). Automaticity, resources and memory: Theoretical controversies and practical implications. Human Factors, 30, 538-598.

Logan, G. (1990). Repetition priming and automaticity: Common underlying mechanisms? Cognitive Psychology, 22, 1-35.

Logan, G. (1991). Automaticity and memory. In W. Hockley \& S. Lewandowsky (Eds.), Relating theory and data: Essays on human memory in honor of Bennet B. Murdock. Hillsdale, NJ: Erlbaum.

Logan, G. (1992). Shapes of reaction-time distributions and shapes of learning curves: A test of the instance theory of automaticity. Journal of Experimental Psychology: Learning, Memory and Cognition, 18, 883-914.

Logan, G. (1997). Automaticity and reading: Perspectives from the instance theory of automatization. Reading and Writing Quarterly: Overcoming Learning Disabilities, 13, 123-146.

Logan, G., \& Etherton, J. (1998). What is learned during automatization? II. Obligatory encoding of location information. Journal of Experimental Psychology: Human Perception and Performance, 24, 1720-1736.

Logan, G., Taylor, S., \& Etherton, J. (1996). Attention in the acquisition and expression of automaticity. Journal of Experimental Psychology: Learning, Memory, and Cognition, 22, 620-638.

Logan, G., Taylor, S., \& Etherton, J. (1999). Attention and automaticity: Toward a theoretical integration. Psychological Research, 62, 165-181.

Logan, G. D. (2002). An instance theory of attention and memory. Psychological Review, 109, 376-400.

Lovegrove, W. J., Bowling, A., Badcock, D., \& Blackwood, M. (1980). Specific reading disability: Differences in contrast sensitivity as a function of spatial frequency. Science, 210, 439-440.

Lovett, M., Ransby, M., Hardwick, N., Johns, M., \& Donaldson, S. (1989). Can dyslexia be treated? Treatment-specific and generalized treatment effects in dyslexic children's response to remediation. Brain and Language, 37, 90-121.

Lukatela, G., \& Turvey, M. (1994a). Visual lexical access is initially phonological: I. Evidence from associative priming by words, homophones, and pseudohomophones. Journal of Experimental Psychology: General, 123, 331-353.

Lukatela, G., \& Turvey, M. (1994b). Visual lexical access is initially phonological: 2. Evidence from phonological priming by homophones and pseudohomophones. Journal of Experimental Psychology: General, 123, 331-353.

Luo, C., Johnson, R., \& Gallo, D. (1998). Automatic activation of phonological information in reading: Evidence from the semantic relatedness decision task. Memory \& Cognition, 26, 833-843.

Lyon, G. (1995). Toward a definition of dyslexia. Annals of Dyslexia, 45, 3-27.

Lyon, G. R., Shaywitz, S. E., \& Shaywitz, B. A. (2003). A definition of dyslexia. Annals of Dyslexia., 53, 1-14.

MacLeod, A., Buckner, R., Miezin, F., Petersen, S., \& Raichle, M. (1998). Right anterior prefrontal cortex activation during semantic monitoring and working memory. Neurolmage, 7, 41-48.

Marshall, J. C., \& Newcombe, F. (1973). Patterns of paralexia: A psycholinguistic approach. Journal of Psycholinguistic Research, 2, 175-199.

McCandliss, B., Cohen, L., \& Dehaene, S. (2003). The visual word form area: Expertise in reading in the fusiform gyrus. Trends in Cognitive Sciences, 7 293-299.

McCrory, E., Mechelli, A., Frith, U., \& Price, C. (2005). More than words: A common neural basis for reading and naming deficits in developmental dyslexia? Brain, $128,261-267$

McInnes, A., Bedard, A.-C., Hogg-Johnson, S., \& Tannock, R. (2007). Preliminary evidence of beneficial effects of methylphenidate on listening comprehension in children with attention-deficit/hyperactivity disorder. Journal of Child and Adolescent Psychopharmacology, $17,35-49$.

McIntosh, A., Bookstein, F., Haxby, J., \& Grady, C. (1996) Spatial pattern analysis of functional brain images using partial least squares. NeuroImage, 3, 143-157.

McIntosh, A., Nyberg, L., Bookstein, F., \& Tulving, E. (1997). Differential functional connectivity of prefrontal and medial temporal cortices during episodic memory retrieval. Human Brain Mapping, 5, 323-327.

Mehta, M. A., Goodyer, I., \& Sahakian, B. J. (2004). Methylphenidate improves working memory and setshifting in AD/HD: Relationships to baseline memory capacity. Journal of Child Psychology and Psychiatry, 45, 293-305.

Mehta, M. A., Owen, A. M., Sahakian, B. J., Mavaddat, N., Pickard, J. D., \& Robbins, T. W. (2000). Methylphenidate enhances working memory by modulating discrete frontal and parietal lobe regions in the human brain. Journal of Neuroscience, 20, 65.

Morgan, W. P. (1896). A case of congenital word blindness. British Medical Journal, 1378.

Nakamura, K., Dehaene, S., Jobert, A., Le Bihan, D., \& Kouider, S. (2005). Subliminal convergence of Kanji and Kana words: Further evidence for functional parcellation of the posterior temporal cortex in visual word perception. Journal of Cognitive Neuroscience, 17 954-968.

Nakamura, K., Dehaene, S., Jobert, A., Le Bihan, D., \& Kouider, S. (2007). Task-specific change of unconscious neural priming in the cerebral language network. Proceedings of the National Academy of Sciences of the United States of America, 104, 19643-19648.

Nakamura, K., Hara, N., Kouider, S., Takayama, Y., Hanajima, R., Sakai, K., et al. (2006). Task-guided selection of the dual neural pathways for reading. Neuron, 52, 557-564.

Nation, K., \& Snowling, M. (1997). Individual differences in contextual facilitation: Evidence from dyslexia and poor reading comprehension. Unpublished manuscript.

National Reading Panel. (2000). Teaching children to read: An evidence based assessment of the scientific research literature on reading and its implications for reading instruction (NIH Publication No. 00-4754). Washington, DC: US Department of Health and Human Services.

Nicolson, R. I., \& Fawcett, A. J. (1990). Automaticity: A new framework for dyslexia research? Cognition, 35 159-182.

Nicolson, R. I., Fawcett, A. J., \& Dean, P. (2001). Developmental dyslexia: The cerebellar deficit hypothesis. Trends in Neurosciences, 24, 508-511.

Park, L., Nigg, J., Waldman, I., Nummy, K., Huang-Pollock, C., Rappley, M., et al. (2005). Association and linkage of alpha-2A adrenergic receptor gene polymorphisms with childhood ADHD. Molecular Psychiatry, 10, 572-580.

Paulesu, E., Demonet, J.-F., Fazio, F., McCrory, E., Chanoine, V., Brunswick, N., et al. (2001). Dyslexia-cultural diversity and biological unity. Science, 291, 2165-2167. 
Perfetti, C., Bell, L., \& Delaney, S. (1988). Automatic phonetic activation in silent word reading: Evidence from backward masking. Journal of Memory and Language, $27,58-70$

Perie, M., Grigg, W., \& Donahue, P. (2005). National assessment of educational progress: The nation's report card, Reading 2005 (NPN Report No. 2006451). Washington, DC: US Government Printing Office.

Price, C., Moore, C., \& Frackowiak, R. S. J. (1996). The effect of varying stimulus rate and duration on brain activity during reading. Neurolmage, 3, 40-52.

Price, C. J., \& Devlin, J. T. (2003). The myth of the visual word form area. Neurolmage, 19, 473-481.

Price, C. J., \& Devlin, J. T. (2004). The pro and cons of labelling a left occipitotemporal region: "The visual word form area." Neurolmage, 22, 477-479.

Ramos, B., \& Arnsten, A. (2007). Adrendergic pharmacology and cognition: Focus on the prefrontal cortex. Pharmacology \& Therapeutics, 113, 523-536.

Ramus, F., Rosen, S., Dakin, S., Day, B., Castellote, J., White, S., et al. (2003). Theories of developmental dyslexia: Insights from a multiple case study of dyslexic adults. Brain, 126, 841-865

Rastle, K., \& Coltheart, M. (1998). Whammy and double whammy: The effect of length on nonword reading. Psychonomic Bulletin and Review, 5, 277-282.

Rastle, K., \& Coltheart, M. (1999a). Lexical and nonlexical phonological priming. Journal of Experimental Psychology: Human Perception and Performance, 25, 461-481.

Rastle, K., \& Coltheart, M. (1999b). Serial and strategic effects in reading aloud. Journal of Experimental Psychology: Human Perception and Performance, 25, 482-503.

Rayner, K., Foorman, B., Perfetti, C., Pesetsky, D., \& Seidenberg, M. (2001). How psychological science informs the teaching of reading. Psychological Science in the Public Interest, 2, 31-74.

Reynolds, M., \& Besner, D. (2006). Reading aloud is not automatic: Processing capacity is required to generate a phonological code from print. Journal of Experimental Psychology: Human Perception and Performance, 32, 1303-1323.

Richards, T., Corina, D., Serafini, S., Steury, K., Echelard, D., Dager, S., et al. (2000). Effects of a phonologically driven treatment for dyslexia on lactate levels measured by proton MRI spectroscopic imaging. American Journal of Neuroradiology, 21, 916-922.

Richardson, E., Kupietz, S., Winsberg, B., Maitinsky, S., \& Mendell, N. (1988). Effects of methylphenidate dosage in hyperactive reading-disabled children: II. Reading achievement. Journal of the American Academy of Child \& Adolescent Psychiatry, 27, 78-87.

Roman, T., Schmitz, M., Polanczyk, G., Eizirik, M., Rohde, L., Hutz, M. A. J., et al. (2003). Is the alpha-2A adrenergic receptor gene $(A D R A 2 A)$ associated with attentiondeficit/hyperactivity disorder? American Journal of Medical Genetics Part B, Neuropsychiatric Genetics, 120, 116-120.

Rumsey, J. M., Andreason, P., Zametkin, A. J., Aquino, T., King, C., Hamburber, S. D., et al. (1992). Failure to activate the left temporoparietal cortex in dyslexia. Archives of Neurology, 49, 527-534.

Salmelin, R., Service, E., Kiesila, P., Uutela, K., \& Salonen, O. (1996). Impaired visual word processing in dyslexia revealed with magnetoencephalography. Annals of Neurology, 40, 157-162.
Schmithorst, V. J., \& Holland, S. K. (2006). Functional MRI evidence for disparate developmental processes underlying intelligence in boys and girls. NeuroImage, $31,1366-1379$

Schmithorst, V. J., \& Holland, S. K. (2007). Sex differences in the development of neuroanatomical functional connectivity underlying intelligence found using Bayesian connectivity analysis. NeuroImage, 35, 406-419.

Seki, A., Koeda, T., Sugihara, S., Kamba, M., Hirata, Y., Ogawa, T., et al. (2001). A functional magnetic resonance imaging study during reading in Japanese dyslexic children. Brain \& Development, 23, 312-316.

Shafritz, K. M., Marchione, K. E., Gore, J. C., Shaywitz, S E., \& Shaywitz, B. A. (2004). The effects of methylphenidate on neural systems of attention in attention deficit hyperactivity disorder. American Journal of Psychiatry, 161, 1990-1997.

Shaw, P., Lerch, J., Greenstein, D., Sharp, W., Clasen, L., Evans, A., et al. (2006). Longitudinal mapping of cortical thickness and clinical outcome in children and adolescents with attention-deficit/hyperactivity disorder. Archives of General Psychiatry 63, 540-549.

Shaywitz, B., Shaywitz, S., Blachman, B., Pugh, K., Fulbright, R., Skudlarski, P., et al. (2004). Development of left occipito-temporal systems for skilled reading in children after a phonologically-based intervention. Biological Psychiatry, 55, 926-933.

Shaywitz, B., Shaywitz, S., Pugh, K., Mencl, W., Fulbright, R., Skudlarski, P., et al. (2002a). Disruption of posterior brain systems for reading in children with developmental dyslexia. Biological Psychiatry, 52, 101-110.

Shaywitz, B., Skudlarski, P., Holahan, J., Marchione, K., Constable, R., Fulbright, R., et al. (2007). Age-related changes in reading systems of dyslexic children. Annals of Neurology, 61, 363-370.

Shaywitz, B. A., Fletcher, J. M., Holahan, J. M., \& Shaywitz, S. E. (1992). Discrepancy compared to low achievement definitions of reading disability: Results from the Connecticut Longitudinal Study. Journal of Learning Disabilities, 25, 639-648.

Shaywitz, B. A., Holford, T. R., Holahan, J. M., Fletcher, J. M., Stuebing, K. K., Francis, D. J., et al. (1995). A Matthew effect for IQ but not for reading: Results from a longitudinal study. Reading Research Quarterly, 30, 894-906.

Shaywitz, B. A., Shaywitz, S. E., Pugh, K. R., Mencl, W. E., Fulbright, R. K., Skudlarski, P., et al. (2002b). Disruption of posterior brain systems for reading in children with developmental dyslexia. Biological Psychiatry, 52, $101-110$.

Shaywitz, S. (2003). Overcoming dyslexia: A new and complete science-based program for reading problems at any level. New York: Alfred A. Knopf.

Shaywitz, S., Fletcher, J., Holahan, J., Shneider, A., Marchione, K., Stuebing, K., et al. (1999). Persistence of dyslexia: The Connecticut Longitudinal Study at adolescence. Pediatrics, 104, 1351-1359.

Shaywitz, S., Fletcher, J., \& Shaywitz, B. (1994). Issues in the definition and classifiction of attention deficit disorder. Topics in Language Disorders, 14, 1-25.

Shaywitz, S., Morris, R., \& Shaywitz, B. (2008). The education of dyslexic children from childhood to young adulthood. Annual Review of Psychology, 59, 451-475.

Shaywitz, S., Shaywitz, B., Fletcher, J., \& Escobar, M. (1990). Prevalence of reading disability in boys and girls: Results of the Connecticut Longitudinal Study. Journal of the American Medical Association, 264, 998-1002. 
Shaywitz, S., Shaywitz, B., Fulbright, R., Skudlarski, P., Mencl, W., Constable, R., et al. (2003). Neural systems for compensation and persistence: Young adult outcome of childhood reading disability. Biological Psychiatry, 54, 25-33.

Shaywitz, S., Shaywitz, B., Pugh, K., Fulbright, R., Constable, R., Mencl, W., et al. (1998). Functional disruption in the organization of the brain for reading in dyslexia. Proceedings of the National Academy of Science of the United States of America, 95, 2636-2641.

Shaywitz, S. E. (1996). Dyslexia. Scientific American, 275 , 98-104.

Shaywitz, S. E., Escobar, M. D., Shaywitz, B. A., Fletcher, J. M., \& Makuch, R. (1992). Evidence that dyslexia may represent the lower tail of a normal distribution of reading ability. New England Journal of Medicine, 326, 145-150.

Snowling, M. (2000). Dyslexia (2nd ed.). Oxford: Blackwell.

Starrfelt, R., \& Gerlach, C. (2007). The visual what for area: Words and pictures in the left fusiform gyrus. NeuroImage, 35, 334-342.

Stein, J. (2003). Visual motion sensitivity and reading. Neuropsychologia, 41, 1785-1793.

Stein, J., \& Walsh, V. (1997). To see but not to read; The magnocellular theory of dyslexia. Trends in Neurosciences, 20, 147-152.

Tallal, P. (1980). Auditory temporal perception, phonics, and reading disabilities in children. Brain \& Language, 9, 182-198

Tallal, P. (2000). The science of literacy: From the laboratory to the classroom. Proceedings of the National Academy of Science of the United States of America, 97, 2402-2404.

Tallal, P., Miller, S., \& Fitch, R. (1993). Neurobiological basis of speech: A case for the preeminence of temporal processing. Annals of the New York Academy of Science, 682, 27-47.

Temple, E., Deutsch, G., Poldrack, R., Miller, S., Tallal, P., Merzenich, M., et al. (2003). Neural deficits in children with dyslexia ameliorated by behavioral remediation: Evidence from fMRI. Proceedings of the National Academy of Science of the United States of America, 100, 2860-2865.

Temple, E., Poldrack, R., Protopapas, A., Nagarajan, S., Salz, T., Tallal, P., et al. (2000). Disruption of the neural response to rapid acoustic stimuli in dyslexia: Evidence from functional MRI. Proceedings of the National Academy of Science of the United States of America, 97, 13907-13912.
Temple, E., Poldrack, R. A., Salidis, J., Deutsch, G. K., Tallal, P., Merzenich, M. M., et al. (2001). Disrupted neural responses to phonological and orthographic processing in dyslexic children: An fMRI study. NeuroReport, 12, 299-307.

Torgesen, J., Alexander, A., Wagner, R., Rashotte, C., Voeller, K., \& Conway, T. (2001). Intensive remedial instruction for children with severe reading disabilities: Immediate and long-term outcomes from two instructional approaches. Journal of Learning Disabilities, $34,33-58$.

Torgesen, J., Wagner, R., \& Rashotte, C. (1997). Approaches to the prevention and remediation of phonologicallybased reading disabilities. Mahwah, NJ: Erlbaum.

Vaidya, C. J., Austin, G., Kirkorian, G., Ridlehuber, H. W. Desmond, J. E., Glover, G. H., et al. (1998). Selective effects of methylphenidate in attention deficit hyperactivity disorder: A functional magnetic resonance study. Proceedings of the National Academy of Science of the United States of America, 95, 14494-14499.

Valera, E., Faraone, S., Murray, K., \& Seidman, L. (2007) Meta-analysis of structural imaging findings in attention-deficit/hyperactivity disorder. Biological Psychiatry, 61, 1361-1369.

Vinckier, F., Dehaene, S., Jobert, A., Dubus, J. P., Sigman, M., \& Cohen, L. (2007). Hierarchical coding of letter strings in the ventral stream: Dissecting the inner organization of the visual word-form system. Neuron, 55, 143-156.

Vinckier, F., Naccache, L., Papeix, C., Forget, J., HahnBarma, V., Dehaene, S., et al. (2006). "What" and "where" in word reading: Ventral coding of written words revealed by parietal atrophy. Journal of Cognitive Neuroscience, 18, 1998-2012.

Willcutt, E. G., \& Pennington, B. F. (2000). Psychiatric comorbidity in children and adolescents with reading disability. Journal of Child Psychology and Psychiatry and Allied Disciplines, 41, 1039-1048.

Xu, B., Grafman, J., Gaillard, W. D., Ishii, K., Vega-Bermudez, F., Pietrini, P., et al. (2001). Conjoint and extended neural networks for the computation of speech codes: The neural basis of selective impairment in reading words and pseudowords. Cerebral Cortex, 11, 267-277.

Xu, B., \& Perfetti, C. (1999). Nonstrategic subject threshold effects in phonemic masking. Memory \& Cognition, 27, 26-36.

Xue, G., Chen, C., Jin, Z., \& Dong, Q. (2006). Language experience shapes fusiform activation when processing a logographic artificial language: An fMRI training study. NeuroImage, 31, 1315-1326. 
Reproduced with permission of the copyright owner. Further reproduction prohibited without permission. 